\title{
Erratum to "The Role of Neurokinin-1 Receptor in the Microenvironment of Inflammation and Cancer"
}

\author{
Marisa Rosso \\ Research Laboratory on Neuropeptides, Hospital Infantil Universitario Virgen del Rocío, Avenida Manuel Siurot s/n, \\ 41013 Seville, Spain \\ Correspondence should be addressed to Marisa Rosso, marisarossog@gmail.com \\ Received 6 June 2012; Accepted 11 June 2012 \\ Copyright (c) 2012 Marisa Rosso. This is an open access article distributed under the Creative Commons Attribution License, \\ which permits unrestricted use, distribution, and reproduction in any medium, provided the original work is properly cited.
}

It has come to our attention that there is an inaccuracy requiring clarification with respect to two important references cited throughout our paper. First, in the PDF version of the paper in paragraph 2.1 in line 27 (after the word "ErbB family") and in the fourth last line (before the word "Figure 2"), reference [42] is missing. Secondly, on page 4 in the last paragraph and on page 13 in the second paragraph, the corresponding text should have been cited as reference [177] instead of reference [42] in both cases. Unfortunately, these mishaps make it impossible to tract the scientific contribution of others to the paper. We apologize to the authors of these articles and the readership of the journal for these shortcomings. 


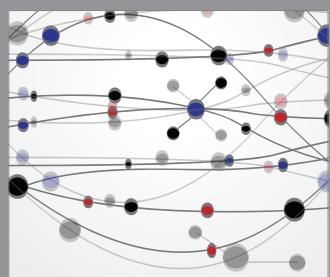

The Scientific World Journal
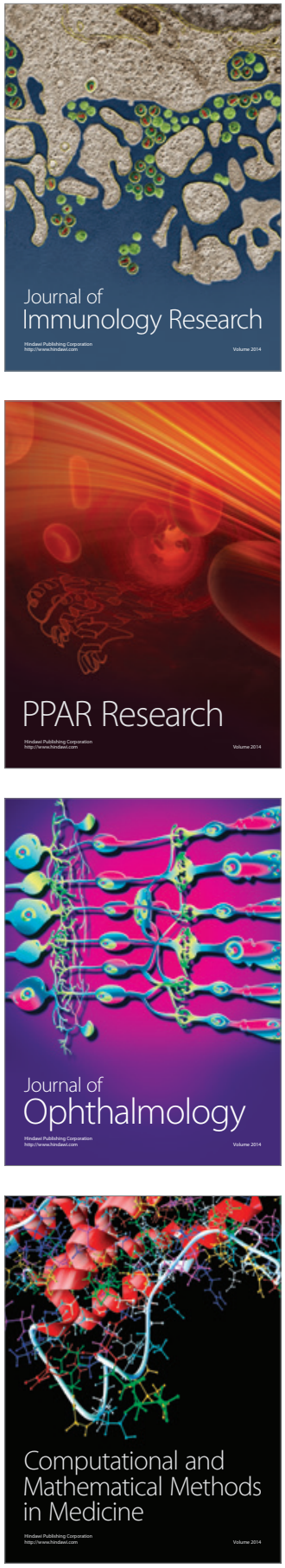

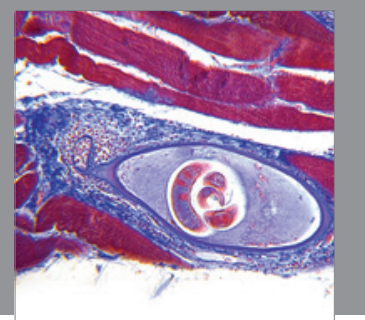

Gastroenterology

Research and Practice
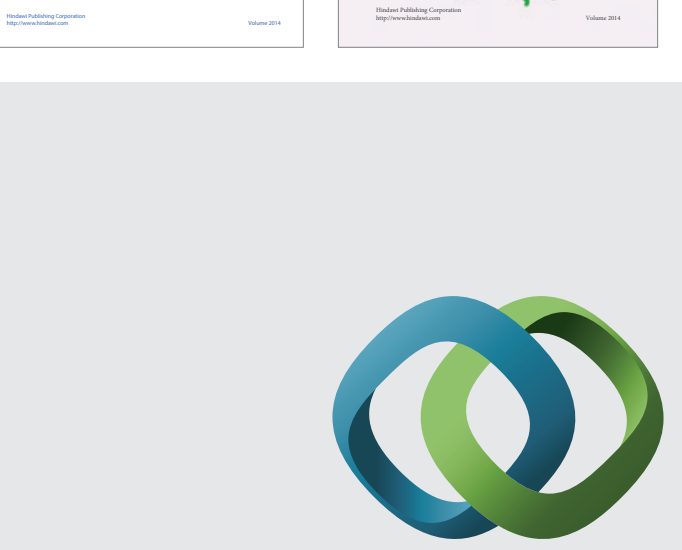

\section{Hindawi}

Submit your manuscripts at

http://www.hindawi.com
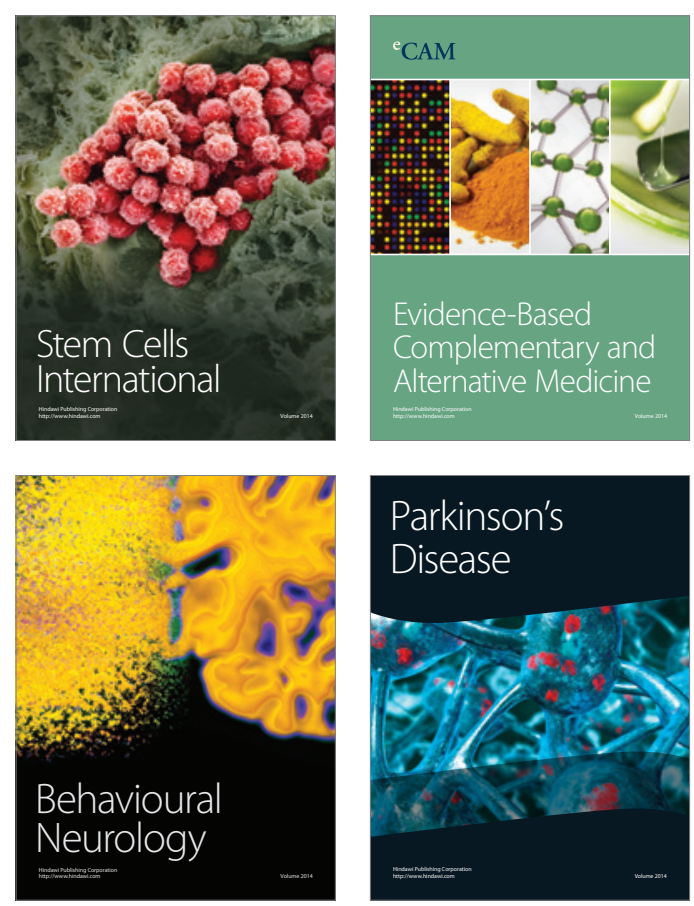

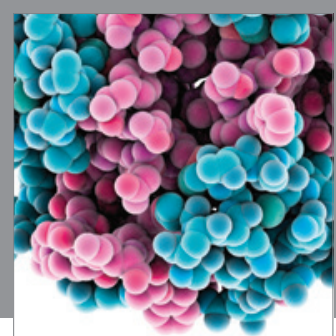

Journal of
Diabetes Research

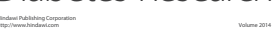

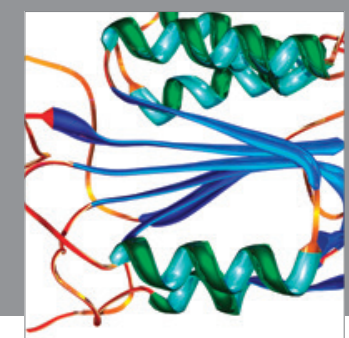

Disease Markers
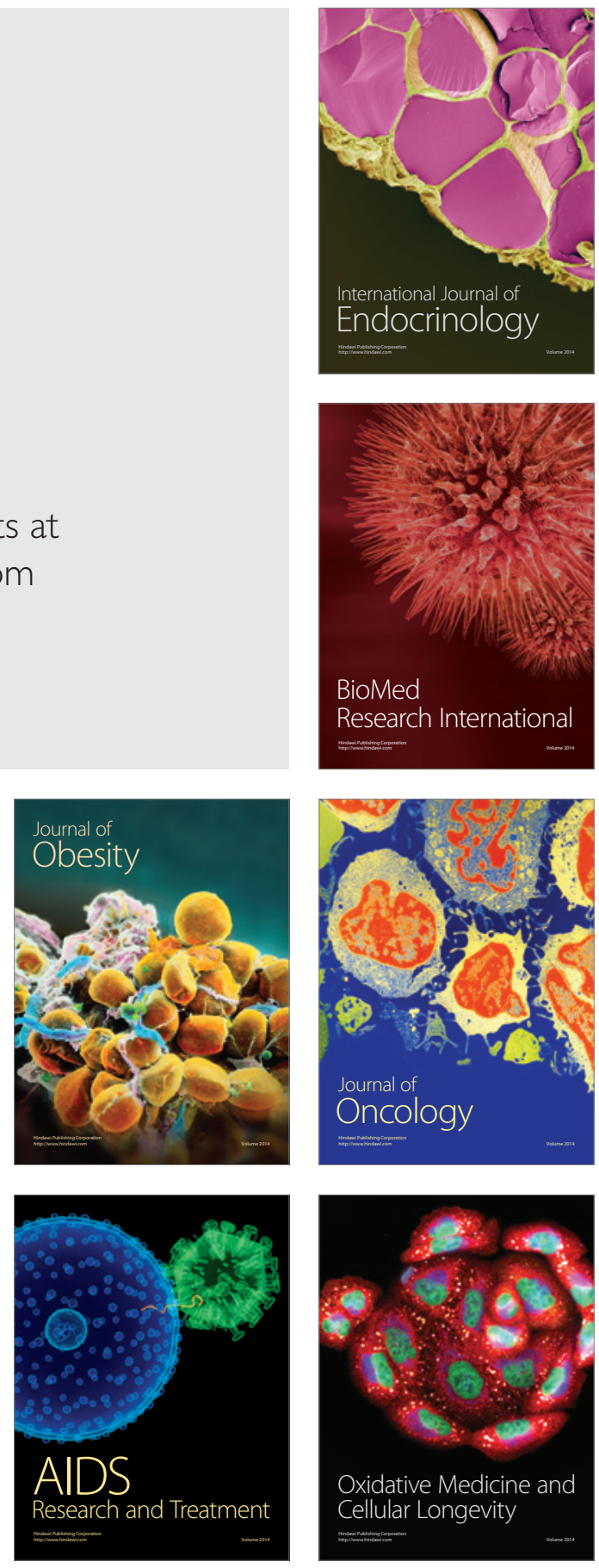